\title{
Caracterización granulométrica y mineralógica de la materia particulada atmosférica en el área cerámica de Castellón
}

\author{
E.T. GÓMEZ'1, T. SANFELIU', J. RIUS'2, D. HERNANDEZ' \\ Unidad de Mineralogía Aplicada y Ambiental. Dpto. Ciencias Experimentales. Universidad Jaume I. Castellón. \\ Inst. Ciència de Materials de Barcelona (CSIC). Campus de la UAB. 08193-Bellaterra. Barcelona
}

\begin{abstract}
Los dos factores fundamentales al evaluar el comportamiento y el origen de los contaminantes particulados atmosféricos son el tamaño de partícula y la composición. En el presente trabajo se ha realizado una caracterización física y mineralógica del MPS ${ }^{1}$ de la Plana de Castellón, captando muestras de particulado atmosférico mediante un impactador de cascada, que permite obtener el material en 7 fracciones de tamaño desde partículas inferiores a $0.5 \mu \mathrm{m}$ a $32 \mu \mathrm{m}$. Se han establecido cinco puntos de muestreo: estación A ubicada en línea de costa, estaciones B, C y E localizadas en poblaciones con industria cerámica, y estación D (también denominada rural) situada en una zona de montaña a $30 \mathrm{~km}$. del centro industrial. Los niveles de concentración obtenidos han sido superiores en las áreas cerámicas respecto a la estación litoral en un 25 a 35\% para el $\mathrm{PST}^{2}$ y el $\mathrm{PM}_{10}{ }^{3}$. En las partículas de menor tamaño, los valores para las tres estaciones tienden a igualarse , siendo ligeramente superiores los niveles en las áreas cerámicas en el caso del $\mathrm{PM}_{2.5}{ }^{4}$, e igual y/o inferior en el $\mathrm{PM}_{1}^{5}$. En la estación de fondo se han obtenido niveles de concentración muy homogéneos para las partículas de 4 a $32 \mu \mathrm{m}$. Se han identificado dos tamaños de partícula característicos, asociados a los niveles máximos de concentración en las áreas cerámicas. La evolución mensual de las concentraciones de partículas enmarcadas en cada uno de estos dos rangos granulométricos ha mostrado diferencias importantes entre las estaciones cerámicas de estudio. Dicha diferenciación se ha asociado a las características topográficas y de ubicación de los puntos respecto al núcleo industrial. El análisis mineralógico ha mostrado una composición muy homogénea en el área cerámica. La distribución granulométrica de las fases minerales ha permitido identificar procesos de aporte natural y antropogénico en el área de estudio.
\end{abstract}

Palabras clave: MPS, impactador de cascada, granulometría, mineralogía, fuentes de aporte

Size particle and mineralogical composition of atmospheric particulate pollutants in the ceramic industrial area of Castellon.

Size and composition are two basic parameters to asses the behaviour and the origin of particulate atmospheric contaminants. The monitoring of the levels of atmospheric particles by means of cascade impactor sampler allow to asses the both parameters together. In this work, the physical and the mineralogical characteristics of TPS in the industrial ceramic area of Castellon are described. Samples of airborne particulate were collected by using a cascade impactor sampler. This collector allow to obtain seven fractions of size particle (range: 0.5 to $32 \mu \mathrm{m}$ ) without filters. Five sampling places were studied. Station A located at coastal line, Station B, Station C and Station E placed at the ceramic industrial area, and Station D (remote station) located at $35 \mathrm{Km}$ from the industrial area. The concentration levels, which were obtained, were upper in the ceramic industrial areas than Station A from 35 to $25 \%$ for TPS and PM $_{10}$. The concentration's values of particles in the minor range of particle size were similar in the three sampling stations, but they were upper in the $\mathrm{PM}_{25}$ fraction and equal in the $\mathrm{PM}_{1}$ fraction. At remote station, the concentration levels, which were obtained, were homogenous for particles from 4 to $32 \mu \mathrm{m}$. Two typical ranges of particle size were identified which are associated to the concentration levels in the ceramic industrial areas. This fact due to explain the existence of particle distribution at different levels of height. The mineralogical analysis has shown that there is a homogenous composition in the ceramic industrial area. The maximum values of the mineral contents, in the size particle distributions, has permitted to identify the natural and the human activities source origins in this area.

Keywords: TSP, cascade impactor sampler, size particle, mineralogy, source origins

\section{INTRODUCCIÓN}

La preocupación de las entidades públicas por el entorno natural ha propagado el desarrollo de nuevos decretos comunitarios sobre calidad medioambiental. Las recientes directivas 96/61/CE (IPPC) de prevención y control integrados de la contaminación, 96/62/CE sobre la evaluación y gestión de la calidad del aire ambiente y 1999/30/CE relativa a los valores límite de contaminantes atmosféricos son ejemplo del esfuerzo legislativo actual. En el ámbito del medio atmosférico de la comarca de la Plana de Castellón, la interrelación y yuxtaposición de procesos de aporte natural y las emisiones procedentes de la industria cerámica generan una compleja problemática medioambiental. En esta situación adquiere una gran relevancia el control de la contaminación por partículas. La caracterización del material y la discriminación de las actividades causantes del aporte es una herramienta de trabajo básica, a fin de optimizar la aplicación de soluciones tácticas y tecnológicas. Dos factores resultan claves en esas determinaciones: el tamano de partícula y la composición mineralógica. El seguimiento de los niveles de partículas mediante un impactador de cascada permite valorar ambos factores conjuntamente. 
En el presente trabajo se muestra el estudio granulométrico y mineralógico de la MPS captada mediante un impactador de cascada de precisión en cuatro estaciones ubicadas en la Plana de Castellón. Dos objetivos se han marcado al desarrollar este plan de trabajo. En primer lugar evaluar la distribución por tamaño de partícula y composición mineral en función de las diferencias geográficas y de actividad industrial de los diferentes puntos de muestreo. En segundo lugar se pretende identificar los rangos de tamaño de partícula y los compuestos minerales asociados a actividades específicas desarrolladas en el área.

\section{PARTE EXPERIMENTAL}

\subsection{Muestreo}

Las muestras de particulado sólido en suspensión han sido obtenidas mediante un impactador de cascada de la marca Retsch modelo PS1. El equipo compuesto por 8 anillos de impactación y programado a un caudal de aspiración de 2.4 $\mathrm{m}^{3} / \mathrm{h}$, ha permitido obtener las muestras fraccionadas en 7 intervalos granulométricos agrupados en:

Anillo $\mathrm{n}^{\mathrm{o}}$ 1: partículas menores de $0.5 \mu \mathrm{m}$; Anillo $\mathrm{n}$ - 2: 0.5-1 $\mu \mathrm{m}$; Anillo $\mathrm{n}^{\mathrm{o}}$ 3: 1-2 $\mu \mathrm{m}$; Anillo $\mathrm{n}^{\mathrm{o}}$ 4: 2-4 $\mu \mathrm{m}$; Anillo $\mathrm{n}^{\mathrm{o}}$ 5: 4-8 $\mu \mathrm{m}$; Anillo $\mathrm{n}^{\circ}$ 6: 8-15 $\mu \mathrm{m}$; Anillo $\mathrm{n}^{\mathrm{o}}$ 7: 15-32 $\mu \mathrm{m}$. Dichos rangos granulométricos corresponden a medidas en tamaño de partícula aerodinámico a fin de homogeneizar los datos entre los diferentes puntos de muestreo. No se ha considerado el anillo de impactación 8 que recoge el material superior a 32 micras.

Se han realizado dos ciclos de muestreo. El primer ciclo comprende desde septiembre de 1999 a agosto 2000. Se han obtenido muestras alternativas en cuatro puntos de muestreo (estaciones A,B,C,D).Figura 1.

La estación A se ha situado en el casco urbano de la localidad del Grao de Castellón en la terraza de un edificio público a 7 metros sobre el nivel de calle. Dicho punto de estudio se halla a $500 \mathrm{~m}$ del puerto comercial y a $2 \mathrm{Km}$. de un complejo petroquímico. La estación $\mathrm{B}$ se ha ubicado en el centro de la población de Alcora en la terraza de un edificio público a 7 metros sobre el nivel de calle. La localidad se sitúa topográficamente a $60 \mathrm{~m}$ de altura sobre el nivel de base industrial. El tercer punto de muestreo, estación C, se ha situado en el casco urbano de la localidad de Onda en un edificio público a 2 metros sobre el nivel de calle y topográficamente a la misma altura del nivel de base industrial. Ambas estaciones, B y C, se caracterizan por la cercanía (menos de $800 \mathrm{~m}$ ) al núcleo industrial cerámico. La estación $\mathrm{D}$, rural, se ha ubicado en Ludiente un pueblo de montaña con una población inferior a 300 habitantes a $30 \mathrm{Km}$. de los núcleos industriales y $500 \mathrm{~m}$ sobre el nivel de mar. El equipo se ha situado en la terraza de un edificio a $2 \mathrm{~m}$ sobre el nivel de calle.

En el segundo ciclo, a partir de septiembre 2000 hasta diciembre de 2000, se han substituido los muestreos en la estación C por captaciones en un nuevo punto de muestreo (estación E). El objetivo de este cambio es comparar las distribuciones granulométricas entre dos puntos de características similares. La estación E se ha ubicado en la localidad de Vila-real en la terraza de un edificio público a $3 \mathrm{~m}$ sobre el nivel de calle. Al igual que la estación C, el punto de captación se halla a la misma altura topográfica respecto a la actividad industrial.

En la tabla I se muestran los muestreos efectuados en cada una de estas estaciones.

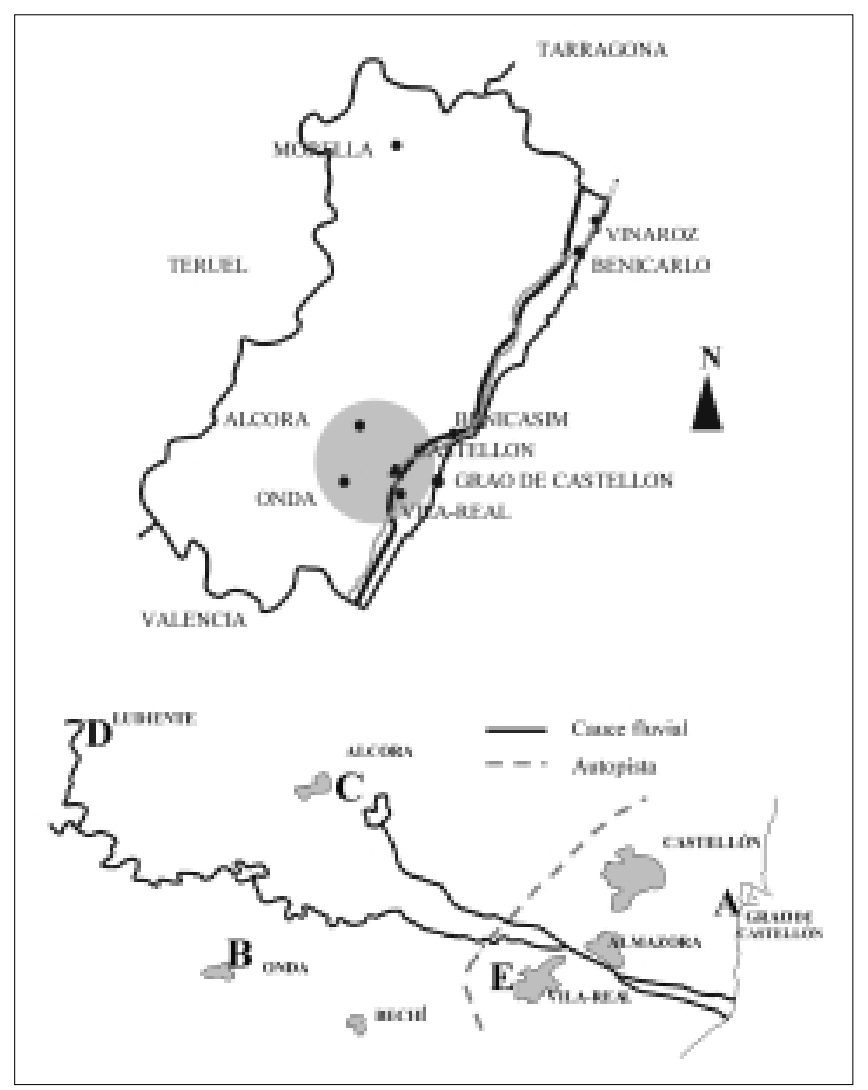

Figura 1. Situación geográfica de los puntos de muestreo.

TABla I. Descripción DE LOS MUESTREOS EFECtUAdOS EN EL ESTUdio.

\begin{tabular}{|r|c|c|l|}
\hline $\begin{array}{r}\text { Punto de } \\
\text { muestreo }\end{array}$ & Periodo de captación & $\begin{array}{c}\mathrm{N}^{\circ} \text { de } \\
\text { muestreos }\end{array}$ & \multicolumn{1}{|c|}{ Meses de captación } \\
\hline Estación A & $\begin{array}{c}3 \text { días consecutivos } \\
\text { por mes } \\
\text { Estación B }\end{array}$ & 6 & Jul.99, Feb.00, Abr.00, Jun.00, Jul.00, Nov.00 \\
ponsecutivos mes & 14 & $\begin{array}{l}\text { Dic.99, Ene.00, Feb.00, Mrz.00, Ab.00, } \\
\text { May.00, Jun.00, Jul.00, Ago.00, Sep.00, } \\
\text { Oct.00 } \\
\text { Estación C }\end{array}$ & $\begin{array}{c}3 \text { días consecutivos } \\
\text { por mes }\end{array}$ \\
Estación D & $\begin{array}{c}6-8 \text { días consecutivos } \\
\text { por mes }\end{array}$ & 7 & $\begin{array}{l}\text { Sep.99, Dic.99, Ene.00, Feb.00, Mrz.00, } \\
\text { Ab.00 May.00, Jun.00, Jul.00 }\end{array}$ \\
Estación E & $\begin{array}{c}3 \text { días consecutivos } \\
\text { por mes }\end{array}$ & 6 & Oct.00, Nov.00, Dic.00 Feb.00, Abr.00, Ago.00, Oct.00 \\
\hline
\end{tabular}

\subsection{Caracterización física}

La caracterización de los niveles de concentración se ha realizado mediante gravimetría a temperatura y humedad controlada de cada uno de los anillos de impactación, antes y después al muestreo. La diferencia del peso junto con el valor total de volumen de aire muestreado ha permitido obtener los datos de concentración en $\mu \mathrm{g} / \mathrm{m}^{3}$ de los siguientes intervalos de tamaño de partículas: $<0.5 \mu \mathrm{m}, 0.5-1 \mu \mathrm{m}, 1-2 \mu \mathrm{m}, 2-4 \mu \mathrm{m}, 4-$ $8 \mu \mathrm{m}, 8-15 \mu \mathrm{m}, 15-32 \mu \mathrm{m}$.

\subsection{Caracterización mineralógica}

Con el objetivo de realizar el estudio mineralógico del particulado atmosférico se ha realizado una extracción mecánica del material captado en cada uno de los anillos de impacta- 
ción. Se ha utilizado un pincel de puntas de plástico finas esterilizado en una solución acuosa ácida.

Dadas las bajas concentraciones másicas correspondientes a cada anillo de impactación (0.5-2 $\mathrm{mg}$ ) se ha concentrado el material, previa realización de los análisis mineralógicos. El objetivo es acumular una cantidad de masa mínima que permita obtener una buena sensibilidad analítica al aplicar la técnica de difracción de rayos X. La acumulación se ha realizado mediante unión vía seca del material de varios anillos de impactación en cuatro fracciones según el tamaño de partícula:

- Fracción 1: 0.5 - $1 \mu \mathrm{m}$ (anillo 2); Fracción 2: 1 - $4 \mu \mathrm{m}$ (anillos 3,4); Fracción 3: 4 - 15 (anillos 5,6,9) $\mu$ m; Fracción 4: 15 $32 \mu \mathrm{m}$ (anillo 7)

Los análisis mineralógicos de la materia particulada concentrada en estas fracciones han sido realizados mediante la técnica de difracción de rayos $X$ en polvo cristalino. El equipo utilizado ha sido un Siemens D5000D con geometría BraggBretano $\theta: 2 \theta$. La identificación de las fases cristalinas presentes se ha realizado mediante el software asociado al equipo Diffract plus XRD Evaluation Program.

Posteriormente, con el objetivo de obtener un valoración semicuantitativa de los minerales mayoritarios presentes en las muestras, se aplicó el método diseñado por Chung ${ }^{(1)}$, siguiendo los procedimientos desarrollados por Boix ${ }^{(2)}$.

\section{RESULTADOS}

\subsection{Niveles de concentración de partículas}

Los datos promediados a partir de todos los periodos de muestreo se hallan expuestos en la tabla II. Se presentan los valores de PST, $\mathrm{PM}_{10}, \mathrm{PM}_{2.5}$ y $\mathrm{PM}_{1}$ calculados mediante interpolación a partir de las curvas acumuladas de distribución granulométrica.

TABLA II. NIVELES DE CONCENTRACIÓN EN $\mu \mathrm{g} / \mathrm{m}^{3}$ EN LOS PUNTOS DE MUESTREO.

\begin{tabular}{|c|c|c|c|c|c|c|c|c|c|c|c|c|c|}
\hline \multirow[t]{3}{*}{ Estación } & \multirow[t]{3}{*}{$\begin{array}{c}\mathbf{N}^{0} \\
\text { muestras }\end{array}$} & \multicolumn{12}{|c|}{ Fracción en $\mu \mathrm{g} / \mathbf{m}^{3}$} \\
\hline & & \multicolumn{3}{|c|}{ PST } & \multicolumn{3}{|c|}{$\mathbf{P M}_{10}$} & \multicolumn{3}{|c|}{$\mathrm{PM}_{2.5}$} & \multicolumn{3}{|c|}{$\mathrm{PM}_{1}$} \\
\hline & & Rango & $\mathrm{X}$ & $S_{n-1}$ & Rango & $\mathrm{X}$ & & Rango & $\mathrm{X}$ & & Rango & $X$ & \\
\hline $\begin{array}{c}\text { A } \\
\text { Grao de } \\
\text { Castellón }\end{array}$ & 6 & $50-73$ & 62 & 12 & $38-56$ & 47 & 12 & $13-28$ & 23 & 8 & $7-17$ & 14 & 5 \\
\hline $\begin{array}{c}\text { B } \\
\text { Alcora }\end{array}$ & 14 & $63-139$ & 90 & 22 & $35-109$ & 65 & 20 & $18-51$ & 32 & 10 & $11-25$ & 16 & 5 \\
\hline $\begin{array}{c}\mathrm{C} \\
\text { Onda }\end{array}$ & 9 & $60-139$ & 86 & 33 & $45-109$ & 68 & 28 & $20-41$ & 31 & 8 & $12-23$ & 17 & 4 \\
\hline $\begin{array}{c}\text { D } \\
\text { Est. } \\
\text { rural }\end{array}$ & 7 & $18-51$ & 26 & 11 & $12-35$ & 21 & 9 & $6-14$ & 11 & 5 & $4-10$ & 7 & 3 \\
\hline
\end{tabular}

$\mathrm{X}$ : promedio

$\mathrm{S}_{\mathrm{n}-1}$ : desviación estandard

Como puede observarse en dicha tabla, los valores obtenidos en las áreas cerámicas son siempre superiores en todos los rangos granulométricos. Los niveles en la estación C (Alcora) varían en un rango comprendido entre 63-139 $\mu \mathrm{g} / \mathrm{m}^{3}$ en el PST, 35- $109 \mu \mathrm{g} / \mathrm{m}^{3}$ para el $\mathrm{PM}_{10}$ y $18-51 \mu \mathrm{g} / \mathrm{m}^{3}$ en la granulometría $\mathrm{PM}_{25}$. Corresponden los mínimos al mes de mayo y los máximos al mes de enero. En la estación B (Onda) los valores varían entre 60-139 $\mu \mathrm{g} / \mathrm{m}^{3}$ en relación al PST, 45-109 $\mu \mathrm{g} / \mathrm{m}^{3}$ en el $\mathrm{PM}_{10}$ y 20-41 $\mu \mathrm{g} / \mathrm{m}^{3}$ en el $\mathrm{PM}_{2.5}$.

En la estación litoral los valores son inferiores y más constantes, variando entre 50 y $73 \mu \mathrm{g} / \mathrm{m}^{3}$ en el PST, 38 y $56 \mu \mathrm{g} / \mathrm{m}^{3}$ en la fracción $\mathrm{PM}_{10}$ y 13 a $28 \mu \mathrm{g} / \mathrm{m}^{3}$ en la granulometría correspondiente al $\mathrm{PM}_{2.5}$.

Los niveles de concentración más bajos se obtienen en la estación de fondo (D), hallándose los valores de PST entre 18$51 \mu \mathrm{g} / \mathrm{m}^{3}$, en el $\mathrm{PM}_{10} 12-32 \mu \mathrm{g} / \mathrm{m}^{3}$ y 6-17 $\mu \mathrm{g} / \mathrm{m}^{3}$ en relación al $\mathrm{PM}_{2,5}$.

\subsection{Distribuciones granulométricas.}

Los datos obtenidos para cada fracción granulométrica correspondientes a las distintas estaciones de muestreo se han transformado en porcentajes relativos a su concentración total. En la tabla III se presentan dichos valores.

TABLA III. VALORES EN \% CORRESPONDIENTES A CADA FRACCIÓN GRANULOMÉTRICA.

\begin{tabular}{|c|c|c|c|c|c|c|c|c|c|c|c|c|c|c|}
\hline \multirow{3}{*}{ Estación } & \multicolumn{14}{|c|}{ Fracción en \% } \\
\hline & \multicolumn{2}{|c|}{$<0.5$} & \multicolumn{2}{|c|}{$0.5-1$} & \multicolumn{2}{|r|}{$1-2$} & \multicolumn{2}{|c|}{$2-4$} & \multicolumn{2}{|c|}{$4-8$} & \multicolumn{2}{|c|}{ 8-15 } & \multicolumn{2}{|c|}{$15-32$} \\
\hline & $\mathbf{X}$ & Rango & $\mathbf{x}$ & Rango & $\mathbf{X}$ & Rango & $\mathbf{X}$ & Rango & $\mathbf{x}$ & Rango & $\mathbf{x}$ & Rango & $\mathbf{x}$ & Rango \\
\hline A & 12 & $8-19$ & 9 & $6-12$ & 10 & $8-14$ & 16 & $14-19$ & 21 & $16-33$ & 20 & $15-27$ & 12 & 7-14 \\
\hline B & 10 & $7-14$ & 8 & $6-10$ & 13 & $11-15$ & 18 & $14-22$ & 19 & $17-21$ & 14 & 11-17 & 18 & 11.24 \\
\hline $\mathrm{C}$ & 13 & $9-18$ & 8 & $6-11$ & 11 & $7-18$ & 16 & 15-19 & 22 & 9-35 & 15 & $9-22$ & 15 & 13-27 \\
\hline D & 15 & $11-22$ & 8 & $7-9$ & 11 & $7-15$ & 17 & $11-26$ & 15 & 11-21 & 19 & $14-21$ & 15 & $13-16$ \\
\hline
\end{tabular}

Los datos en porcentaje relativo indican los intervalos de tamaño que presentan un mayor enriquecimiento en cada estación, independientemente de su concentración absoluta. Así observamos, que la estación litoral (A) se halla enriquecida en las partículas comprendidas de 0.5 a $1 \mu \mathrm{m}$, y de 4 a $15 \mu \mathrm{m}$. La estación ubicada en Onda (C) destaca por mayores porcentajes relativos en las partículas menores de $0.5 \mu \mathrm{m}$, y en el intervalo granulométrico de 4 a $8 \mu \mathrm{m}$. Los datos correspondientes a la estación de Alcora (B) indican un enriquecimiento en las partículas comprendidas en el rango 1 a $4 \mu \mathrm{m}$. Finalmente la estación rural presenta un importante proporción en las partículas menores de $0.5 \mu \mathrm{m}$, y en las comprendidas en el rango 8 a $15 \mu \mathrm{m}$.

Estos valores en porcentaje se reflejan en los datos de concentración absoluta en $\mu \mathrm{g} / \mathrm{m}^{3}$ representados en la figura 2, correspondiendo cada barra a uno de los muestreos efectuados.

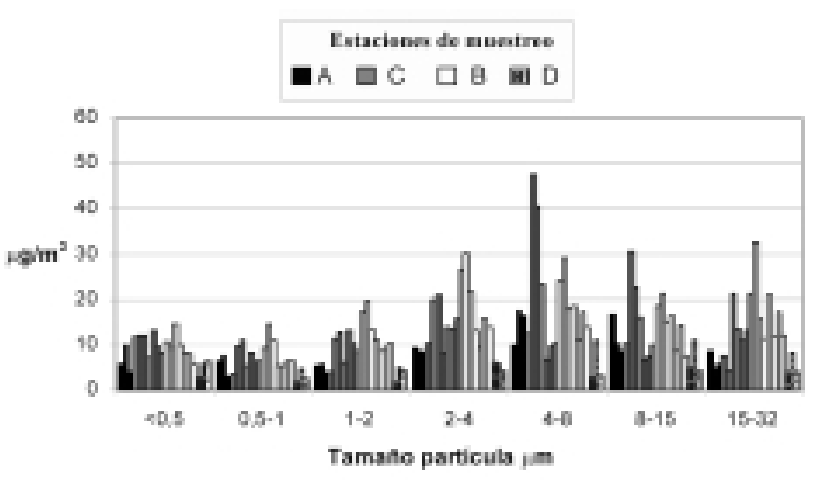

Figura 2. Concentraciones en $\mu \mathrm{g} / \mathrm{m}^{3}$ de las fracciones comprendidas de 0.5 a $8 \mu \mathrm{m}$. 
Se observa que las estaciones ubicadas en las áreas cerámicas presentan valores muy superiores en las partículas comprendidas de 1 a $8 \mu \mathrm{m}$. Los valores más altos en este rango granulométrico coinciden además con los máximos niveles de concentración de PST y PM $_{10}$ en ambas estaciones. Dentro de este rango se presentan dos máximos correspondientes a cada una de las estaciones cerámicas, en Alcora destacan en importancia las partículas comprendidas entre $2-4 \mu \mathrm{m}$, mientras que en Onda los máximos se sitúan en las fracciones de $4-8 \mu$.

En el estudio de la evolución mensual de los valores absolutos (en $\mu \mathrm{g} / \mathrm{m}^{3}$ ) correspondientes a cada fracción granulométrica ha destacado la importancia de estos dos intervalos de partícula en las áreas de concentración industrial cerámica.

En la localidad de Alcora (estación B) se observa un descenso en todas las fracciones granulométricas durante los meses de abril y mayo respecto a los meses de invierno, dando una tasa de reducción de partículas del $70 \%$ en el intervalo de 2 a $4 \mu \mathrm{m}$, y de $45-50 \%$ en el resto de las fracciones, figura 3 .

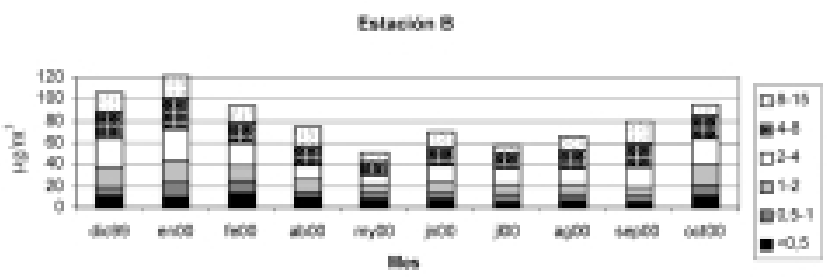

Figura 3. Evolución mensual de los valores absolutos en $\mu \mathrm{g} / \mathrm{m}^{3}$ en la estación B ubicada en la localidad de Alcora

A partir de estos meses las partículas menores de $0.5 \mu \mathrm{m}$ descienden gradualmente conforme se avanza a los meses de verano. Por el contrario, las partículas entre 0.5 y $2 \mu \mathrm{m}$ aumentan un $16 \%$, las comprendidas de 2 a $4 \mu \mathrm{m}$ un $30 \%$ y el intervalo granulométrico de 4 a $8 \mu \mathrm{m}$ un $20 \%$. La mayor recarga de partículas en esta localidad se da en las partículas de 2 a $4 \mu \mathrm{m}$, pero dicha recuperación no es tan rápida como el descenso sufrido en abril-mayo, no alcanzando los niveles dados en invierno.

La evolución mensual en los niveles de concentración obtenidos en la estación de Onda, figura 4, tiene un comportamiento similar al seguido en Alcora .

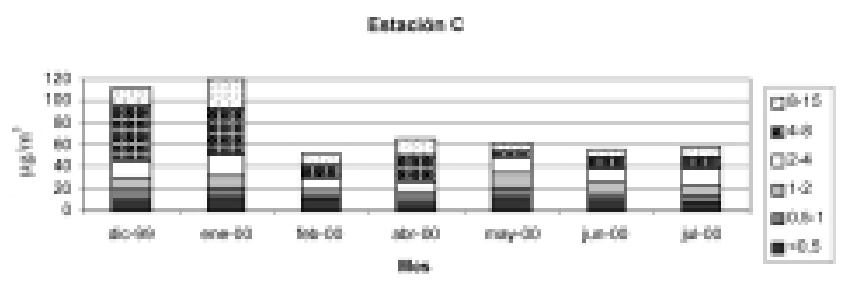

Figura 4. Evolución mensual de los valores absolutos en $\mu \mathrm{g} / \mathrm{m}^{3}$ en la estación C ubicada en la localidad de Onda

Las fracciones comprendidas entre 0.5 y $4 \mu \mathrm{m}$ sufren un descenso en el mes de abril respecto a los meses de invierno, con una tasa de reducción de partículas comprendida entre el $45-50 \%$. Sin embargo se produce una nueva recarga y por lo tanto un aumento de los niveles de concentración en estos tamaños de partícula durante mayo. Posteriormente, en junio y julio se observa un descenso gradual de las fracciones de 0.5 a $2 \mu \mathrm{m}$. En el intervalo de partículas más gruesas, el descenso más acusado se produce en mayo, siendo la tasa de reducción mayor (70\%) en las partículas comprendidas en el rango de 4 a $8 \mu \mathrm{m}$. A partir de este mes se produce, al igual que en la localidad de Alcora, un aumento de las concentraciones; en el mes de julio: del $12 \%$ en las partículas de 2 a $4 \mu \mathrm{m}$ y del $38 \%$ en el intervalo 4 a $8 \mu \mathrm{m}$. Se observa por lo tanto que en la localidad de Onda la mayor tasa de reducción y de recarga se da en las partículas englobadas en la fracción 4 a $8 \mu \mathrm{m}$, siendo más rápida también en este caso la tasa de reducción.

Un comportamiento análogo se ha obtenido en el estudio de la evolución mensual de los niveles de partículas obtenidos en la estación E, figura 5.

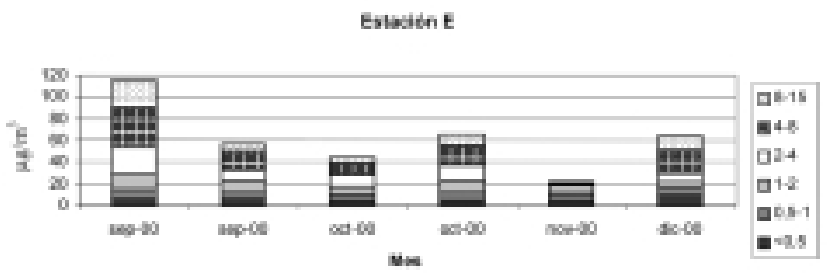

Figura 5. Evolución mensual de los valores absolutos en $\mu \mathrm{g} / \mathrm{m}^{3}$ en la estación E ubicada en la localidad de Vila-real.

Como se puede observar en dicha figura de septiembre a octubre se produce una reducción de los niveles de partículas en todos los rangos granulométricos. La tasa de reducción es de un $74 \%$ en las partículas de 4 a $8 \mu \mathrm{m}$, y del 30 al $56 \%$ en el resto de intervalos granulométricos. Tras un aumento en un segundo muestreo efectuado en octubre se produce una reducción de las concentraciones en noviembre. Finalmente, en diciembre se obtienen valores altos con una tasa de recarga , a partir de noviembre, del $91 \%$ en rango granulométrico de 4 a $8 \mu \mathrm{m}$ y de 20 a $60 \%$ en el resto de tamaños de partícula.

En la estación ubicada en el Grao de Castellón, estación A, no existen fluctuaciones tan marcadas en los niveles de concentración de partículas de diferentes intervalos granulométricos, figura 6.

Estasien A

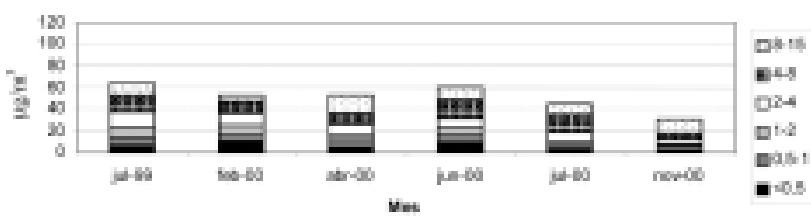

Figura 6. Evolución mensual de los valores absolutos en $\mu \mathrm{g} / \mathrm{m}^{3}$ en la estación C ubicada en el área del Grao de Castellón.

Se observa un aumento de las partículas gruesas de 4 a $8 \mu \mathrm{m}$ en los meses estivales (julio 1999, junio y julio 2000) respecto al resto de muestreos efectuados. En relación a las tasas de recarga y reducción no se pueden extraer tendencias significativas dado el menor número de muestreos. Si se puede identificar un descenso de los niveles de concentración de febrero a abril, siendo la tasa de reducción del $49 \%$ en las partículas menores de $0.5 \mu \mathrm{m}$, del $37 \%$ en el intervalo de 1 a $2 \mu \mathrm{m}$, y del $2 \%$ al $18 \%$ en el resto de rangos granulométricos. 
Igualmente, en el descenso de concentraciones entre junio y julio se produce una reducción del $60 \%$ en las partículas desde $1 \mu \mathrm{m}$ a menores de $0.5 \mu \mathrm{m}$, del $30 \%$ en las comprendidas en el rango de 1 a $2 \mu \mathrm{m}$ y del $7 \%$ en el intervalo de 2 a $8 \mu \mathrm{m}$. Si existe, por tanto, una cierta tendencia a una mayor tasa de reducción en las partículas finas en la estación A ante periodos de descenso de los niveles generales de concentración.

En la estación rural (D), más que la existencia de una evolución mensual, las variaciones de las concentraciones se asocian más bien a variables meteorológicas puntuales. En la figura 7 se ha representado la evolución mensual de los niveles de concentración en función del tamaño de partícula en la estación D.

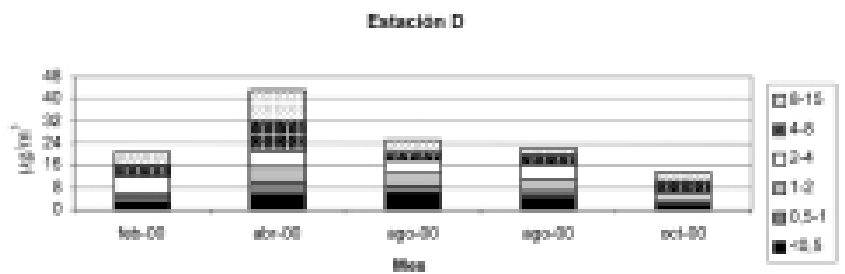

Figura 7. Evolución mensual de los valores absolutos en $\mu \mathrm{g} / \mathrm{m}^{3} \mathrm{en} \mathrm{la}$ estación D ubicada en el área rural.

El muestreo efectuado durante el mes de abril se realizó en condiciones meteorológicas de vientos de alta intensidad. Las concentraciones obtenidas evidencian un considerable aumento con respecto a muestreos anteriores; en todos los rangos granulométricos con la mayor recarga en las fracciones comprendidas entre 1 a $2 \mu \mathrm{m}$, y entre 4 a $32 \mu \mathrm{m}$.

Al estudiar la evolución mensual en la estación D, obviando el muestreo efectuado en abril dada la alta intensidad de los vientos, se observa un comportamiento estacional diferente entre partículas gruesas y finas. En los muestreos efectuados en febrero, agosto y octubre los valores en las partículas enmarcadas en el intervalo de 4 a $32 \mu \mathrm{m}$ son bastante constantes, y muy igualados ( 3 a $3.8 \mu \mathrm{g} / \mathrm{m}^{3}$ ) en el rango de 4 a $8 \mu \mathrm{m}$. Por el contrario las partículas comprendidas entre 0.5 a $2 \mu \mathrm{m}$ presentan una clara evolución estacional presentando mayores niveles en la estación calurosa, con valores muy altos en las menores a $0,5 \mu \mathrm{m}$.

Así puede asignarse a las partículas finas un marcado origen antropogénico, en donde el aumento de temperatura y radiación solar facilitará su movilidad desde los focos de emisión a través de los valles fluviales, en este caso a través del cauce del Río Mijares y afluentes asociados. Estudios realizados en zonas rurales del área costero mediterránea han evidenciado igualmente un aumento de las concentraciones de partículas hacia las épocas calurosas, Querol ${ }^{(3)}$.

Por su parte, el constante valor obtenido en las partículas gruesas es más indicativo de un origen fijo asociado en gran medida al aporte natural dado en la zona. Este hecho nos permite estimar un valor aproximado del nivel de fondo característico de la comarca de estudio.

\subsection{Composición mineralógica}

Los porcentajes de las fases mayoritarias obtenidos tras la aplicación del método de análisis semicuantitativo a las fracciones concentradas $(1,2,3,4)$ y correspondientes a las estaciones ubicadas en el Grao de Castellón (A), Alcora (B) y área rural (D)son expuestos en las tablas IV y V.
TABLA IV. PorcentAJES CORRESPONDIENTES A LAS FASES MINERALES MAYORITARIAS IDENTIFICADAS EN LA FRACCIÓN 1 Y 2.

\begin{tabular}{|c|c|c|c|c|c|c|}
\hline \multirow[b]{2}{*}{ Fase mineral } & \multicolumn{3}{|c|}{ Fracción 1} & \multicolumn{3}{|c|}{ Fracción 2} \\
\hline & $\begin{array}{c}\text { Estación } \\
\text { A }\end{array}$ & $\begin{array}{c}\text { Estación } \\
\mathrm{C}\end{array}$ & $\begin{array}{c}\text { Estación } \\
\text { D }\end{array}$ & $\begin{array}{c}\text { Estación } \\
\mathrm{A}\end{array}$ & $\begin{array}{c}\text { Estación } \\
\quad \mathrm{C}\end{array}$ & $\begin{array}{c}\text { Estación } \\
\text { D }\end{array}$ \\
\hline Cuarzo & $17-21$ & $7-20$ & $4-13$ & $3-31$ & 11 & $8-22$ \\
\hline Illita/mica & $<$ l.d. & $<$ l.d.-16 & < l.d.-17 & < l.d.-10 & $11-21$ & <l.d. \\
\hline Caolinita & $<$ l.d. & $18-32$ & < l.d.-53 & $<$ I.d. & $29-40$ & $<$ 1.d.-27 \\
\hline Calcita & < l.d.-28 & $7-11$ & $2-32$ & $15-37$ & $14-27$ & $18-34$ \\
\hline Dolomita & < l.d.-16 & $3-13$ & $4-11$ & 11-19 & $4-8$ & $5-7$ \\
\hline Hematites & $<$ l.d.-29 & $<$ l.d.-17 & $<$ l.d. & < l.d.-16 & $1-4$ & $8-20$ \\
\hline Feldespato K & $<$ l.d.-3 & $<$ l.d. & $<$ l.d. & $<$ l.d. & $1-2$ & $<$ l.d.-2 \\
\hline Plagioclasa $\mathrm{Na}$ & $7-55$ & $3-36$ & $7-14$ & $5-20$ & $2-6$ & $4-8$ \\
\hline Clorita & $<$ l.d.-7 & 11 & $<$ l.d.-5 & < 1.d.-4 & $9-12$ & < 1.d.-11 \\
\hline Yeso & < I.d.-17 & $7-19$ & $11-21$ & < l.d.-17 & $1-3$ & 4-9 \\
\hline Halita & $<$ l.d. & $2-4$ & < l.d.-5 & < l.d.-14 & $<$ l.d.-2 & 8 \\
\hline Sili. Circón & $<$ l.d. & $<$ l.d. & $<$ l.d.-1 & $<$ l.d. & <l.d. & $<$ l.d. \\
\hline
\end{tabular}

datos en $\%$

$<1$.d.: inferior al límite de detección

TABla V. Porcentajes CORRESPONDIENTES A LAS FASES MINERALES MAYORITARIAS IDENTIFICADAS EN LA FRACCIÓN 3 Y 4.

\begin{tabular}{|c|c|c|c|c|c|c|}
\hline & \multicolumn{3}{|c|}{ Fracción 3} & \multicolumn{3}{|c|}{ Fracción 4} \\
\hline Fase mineral & $\begin{array}{c}\text { Estación } \\
\mathrm{A}\end{array}$ & $\begin{array}{c}\text { Estación } \\
\mathrm{C}\end{array}$ & $\begin{array}{c}\text { Estación } \\
\text { D }\end{array}$ & $\begin{array}{c}\text { Estación } \\
\mathrm{A}\end{array}$ & $\begin{array}{c}\text { Estación } \\
\mathrm{C}\end{array}$ & $\begin{array}{c}\text { Estación } \\
\text { D }\end{array}$ \\
\hline Cuarzo & $4-5$ & $5-22$ & $4-16$ & $2-13$ & $8-24$ & $6-8$ \\
\hline Illita/mica & $<$ l.d.-11 & $10-25$ & $12-24$ & 5 & $13-34$ & $16-18$ \\
\hline Caolinita & $<$ l.d.-38 & 24-45 & $14-26$ & $7-9$ & $22-34$ & $19-29$ \\
\hline Calcita & $18-23$ & $7-26$ & $14-43$ & 15 & $8-24$ & $10-15$ \\
\hline Dolomita & $6-47$ & 3-9 & 8 & $44-62$ & $2-9$ & $22-23$ \\
\hline Hematites & $<$ l.d.-3 & $<$ l.d.-3 & < l.d. & $<$ l.d. & 3-7 & <l.d. \\
\hline Feldespato K & $<$ l.d.-18 & 3-7 & < l.d.-2 & $<$ l.d.-2 & $1-4$ & $<$ l.d. -3 \\
\hline Plagioclasa Na & 8-13 & $1-2$ & $9-10$ & 4-10 & $2-5$ & $5-6$ \\
\hline Clorita & $<$ l.d. & $6-12$ & < l.d.-5 & $<$ l.d. & $6-13$ & $8-10$ \\
\hline Yeso & $4-6$ & $1-2$ & <l.d.-2 & $1-2$ & $<$ l.d.-2 & 2 \\
\hline Halita & $<$ l.d. & $<$ l.d. & $<$ l.d.-3 & $<$ l.d. & <l.d. & <l.d. \\
\hline Si. Circón & < l.d.-1 & $<$ l.d. & $<$ l.d. & $<$ l.d.-1 & < l.d. & <l.d. \\
\hline
\end{tabular}

datos en $\%$

$<$ 1.d.: inferior al límite de detección

El análisis de los datos expuestos en dichas tablas indica que el grado de homogeneidad en la composición mineralógica de las muestras es la característica clave que define los tres ambientes estudiados. La estación B ubicada en el área cerámica presenta una distribución mineral por tamaño de partícula muy homogénea. Se ha identificado un enriquecimiento constante en función de la fracción granulométrica de varios compuestos cristalinos. La fracción $1(0.5-1 \mu \mathrm{m})$ presenta en todas las series estudiadas un incremento en porcentaje respecto al resto de fracciones de los siguientes compuestos minerales : Plagioclasa $\mathrm{Na}$, yeso y halita. En la figura 8 se ve el comportamiento seguido por estos compuestos en tres de los meses muestreados.

La fracción $2(1-4 \mu \mathrm{m})$ presenta un enriquecimiento constante en los compuestos caolinita y calcita, así como una tendencia a aumentar el contenido del mineral illita. Además dicha fracción se caracteriza por poseer el pico de niveles máximos de concentración en la localidad de Alcora. En la figura 9 se muestra la distribución de dichos minerales. 


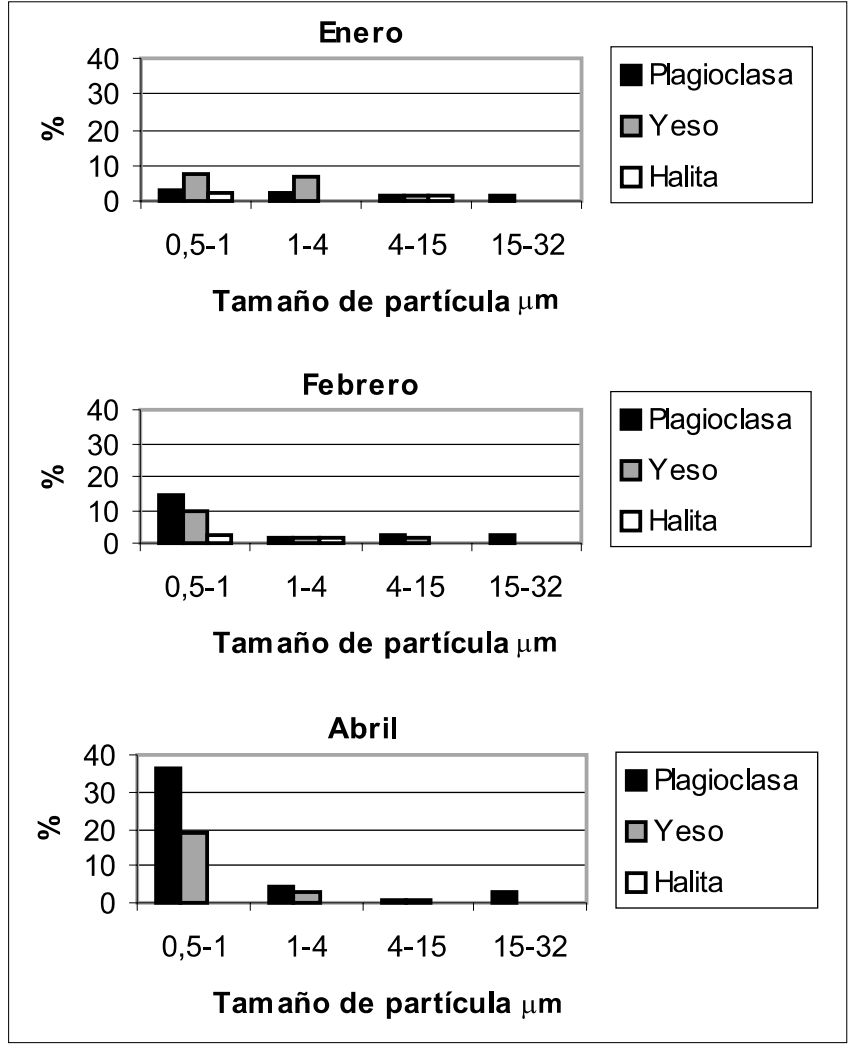

Figura 8. Distribución granulométrica de los minerales yeso, halita y plagioclasa-Na en la estación B cerámica.

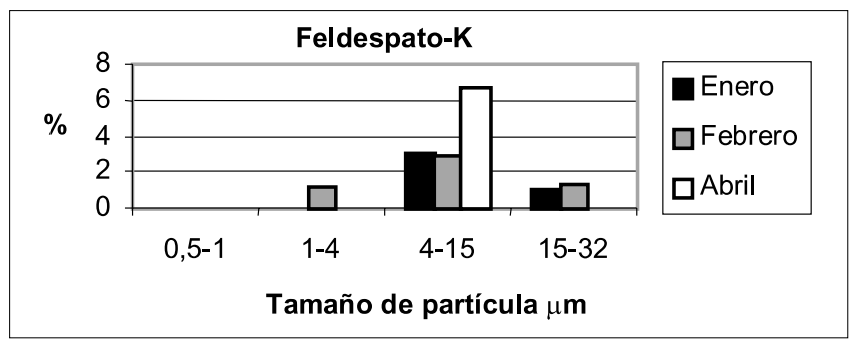

Figura 10. Distribución granulométrica del mineral feldespato-K en la estación B cerámica.

En la fracción 3 (4-15 $\mu \mathrm{m})$ el único mineral que presenta un incremento constante es la fase mineral Feldespato K, figura 10.

La fracción 4 (15-32 $\mu \mathrm{m})$ no muestra ningún enriquecimiento constante de fases cristalinas. Tan sólo una cierta tendencia a aumentar las concentraciones de illita y de hematites.

La estación rural presenta un grado de homogeneidad mineral bajo, identificándose únicamente 3 minerales que exhiben un enriquecimiento en alguna de las fracciones analizadas. Así, la fracción 1 se caracteriza por un enriquecimiento en yeso, presentando además altos contenidos en minerales arcillosos, la fracción 2 en hematites y la fracción 4 en dolomita.

Finalmente, la estación ubicada en el Grao de Castellón muestra un grado de uniformidad mineral nulo, observándose solo un enriquecimiento constante del mineral dolomita en la fracción 4 de mayor tamaño de partícula. Destaca la no identificación de minerales arcillosos en ninguno de los muestreos efectuados en la fracción de partículas inferiores a $1 \mu \mathrm{m}$.

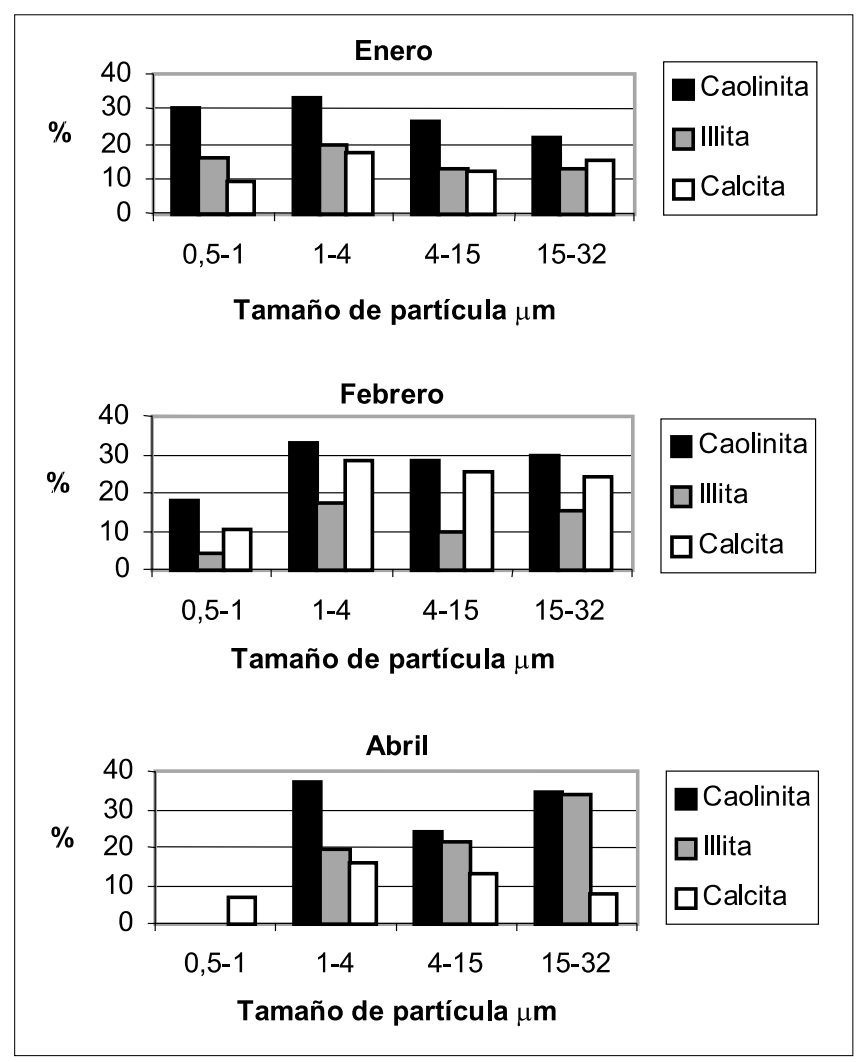

Figura 9. Distribución granulométrica de los minerales caolinita, illita y calcita en la estación B cerámica.

\section{PROCESOS DE APORTE}

\subsection{Procesos de aporte natural}

El análisis mineralógico de muestras obtenidas durante uno de los períodos de muestreo, con condiciones climáticas favorables a la intrusión de material procedente de transporte de larga distancia, ha permitido identificar tendencias significativas ante este proceso de aporte natural.

El periodo de intrusión corresponde al intervalo de tiempo comprendido entre finales de febrero de 2000 a mediados de marzo del mismo año. La identificación de niveles muy altos de concentración de partículas conllevó a la revisión de los mapas de presión atmosférica durante ese intervalo temporal. Se consultaron también los datos expuestos por Avila(4) sobre situaciones meteorológicas típicas de eventos de lluvias de polvo procedente de diferentes áreas del Norte de África (Atlas, Oeste del Sahara, Algeria Central). Existía una gran similitud entre el mapa de isobaras correspondiente al periodo en estudio y el correspondiente al evento de intrusión de material procedente del Oeste del Sahara. Así mismo, los datos facilitados en relación a las imágenes satélite del programa SKIRON, indicados por Querol ${ }^{(5)}$ y ECWGPM ${ }^{(6)}$, corroboraron la existencia del periodo con intrusión de material de transporte de larga distancia.

En la figura 11 se han representado las distribuciones granulométricas correspondientes a este periodo de muestreo y a los efectuados dos meses consecutivos (abril, mayo) en las estaciones $\mathrm{B}$ y C. 


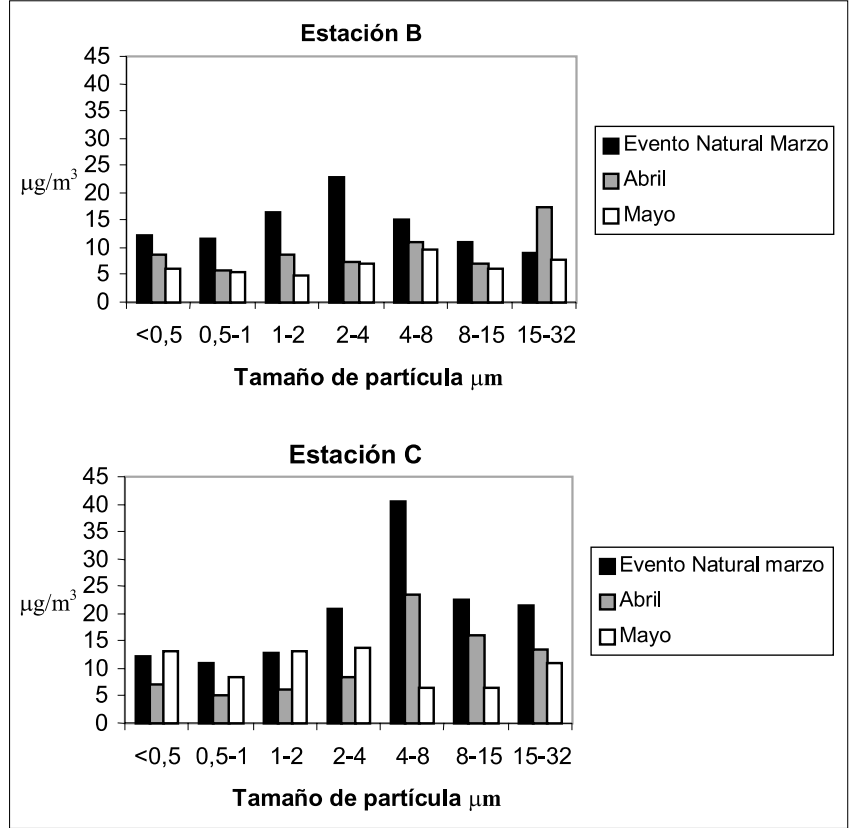

Figura 11. Niveles de concentración en $\mu \mathrm{g} / \mathrm{m}^{3}$ durante el evento de intrusión (marzo) y en los meses de abril y mayo de 2000 en la estación B (muestreos días no laborables) y estación C (muestreos días laborables).

Durante este periodo de muestreo se ha identificado un aumento significativo de partículas comprendidas en el rango de 2 a $8 \mu \mathrm{m}$. Sin considerar el aporte en otros rangos de partícula, en estos tamaños se puede suponer hasta un aumento de concentración de 20 a $30 \mu \mathrm{g} / \mathrm{m}^{3}$.

El análisis mineralógico de las partículas captadas en este intervalo ha mostrado un aumento en el rango de 2 a $4 \mu \mathrm{m}$ de los minerales calcita, illita y hematites aunque en los dos últimos menos significativo. En la fracción de 4 a $8 \mu \mathrm{m}$ se ha observado el aumento en las fases cristalinas illita y caolinita.

Investigaciones realizadas sobre la mineralogía de partículas presentes en lluvias con carga de polvo procedente del Norte de Africa en episodios producidos durante marzo de años anteriores, Avila ${ }^{(7)}$, constataron composiciones enriquecidas en illita y calcita. Tal indicio apoya los incrementos en dichas fases detectados en el presente estudio.

La diferencia entre la composición mineralógica general y la obtenida en el evento de intrusión en las estaciones B y C, muestra un método de trabajo que permite identificar los episodios de mayor contribución de material a partir de procesos naturales de largo transporte. De acuerdo con esto, la identificación de muestras altamente enriquecidas en calcita y en hematites en la fracción 2, juntamente con un gran aumento de los porcentajes de illita y caolinita en la fracción 3, se pueden asociar con una contribución natural adicional. Estas tendencias pueden observarse en la mineralogía obtenida en la estación rural de montaña. Dicho punto se caracteriza por presentar unos niveles de concentración muy homogéneos en las partículas gruesas. La mineralogía asociada a las mismas presenta un enriquecimiento en calcita en las partículas de 2 a $4 \mu \mathrm{m}$, de illita y ligeramente de caolinita en los tamaños de 4 a $15 \mu \mathrm{m}$, y de dolomita en el intervalo de partículas más gruesas $(15-32 \mu \mathrm{m})$. El incremento en dolomita se asocia al sustrato dolomítico predominante que presentan los relieves de la zona, pudiendo relacionarse este tamaño de partícula al aporte de material procedente de la erosión natural eólica. Por su lado el enriquecimiento en calcita de la fracción 2 y de illita y caolinita en la fracción 3 se asemeja más a la distribución aportada por las masas de aire procedente de fuentes alejadas.

\subsection{Procesos de aporte antropogénico}

Los valores más altos de enriquecimiento de fases minerales, en función del tamaño de partícula, ha permitido reconocer diferentes procesos de aporte de aerosol atmosférico. El enriquecimiento de fases en los tamaños de partícula menores de $1 \mu \mathrm{m}$ se ha asociado a actividades antropogénicas o procesos de neoformación en la atmósfera a partir de compuestos emitidos en procesos de alta temperatura y/o combustión. En este sentido, fases como el yeso y la halita son originadas a partir de la reacción de sales mixtas naturales y emisiones de compuestos de azufre y cloro, tal como ha sido demostrado por numerosos autores, Sturges ${ }^{(8)}$, Bergametti ${ }^{(9)}$. Los mayores porcentajes de yeso en la fracción fina $<1 \mu \mathrm{m}$ han sido identificados en la estación de fondo. Este valor apoya los datos aportados por Gillani ${ }^{(10)} \mathrm{y} \mathrm{Zhou}^{(11)}$, sobre los procesos de conversión de calcita a yeso durante el transporte a partir de la oxidación de compuestos sulfatados procedentes de emisiones de $\mathrm{SO}_{x}$. El mineral Plagioclasa Na-Ca entra a formar parte de este grupo. Dicho feldespato sódico se halla enriquecido en la fracción de 0.5 a $1 \mu \mathrm{m}$ de las áreas cerámicas. La figura 12 indica diferente distribución granulométrica de este compuesto en el Grao de Castellón (estación A) y en Alcora (estación B).

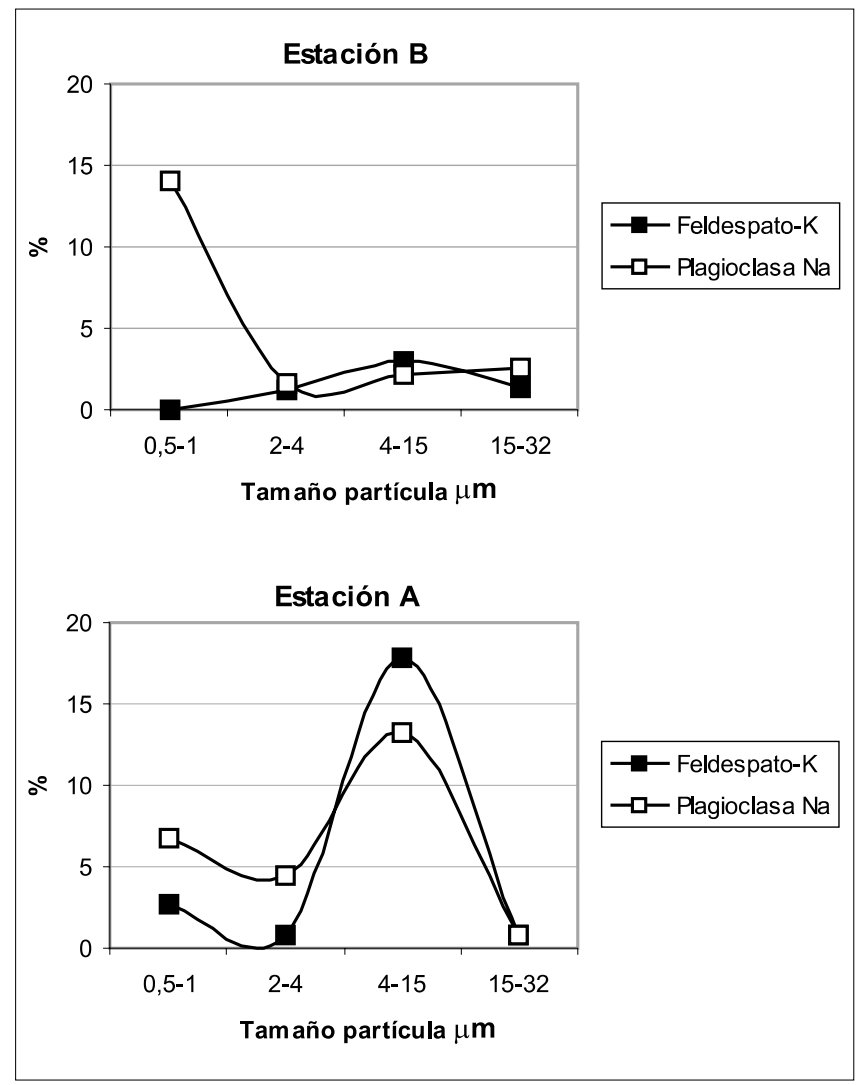

Figura 12. Comparación de las curvas granulométricas de las fases feldespato-K y plagioclasa-Na. 
El feldespato K, en cambio, a pesar de poseer características mineralógicas y petrológicas muy similares, si sigue un comportamiento muy similar en ambas localidades. Ambos tipos de minerales son también utilizados como materias primas en la industria cerámica importados desde el extranjero por vía marítima. La identificación del valor máximo de porcentaje de feldespato K y de plagioclasa Na-Ca en el Grao de Castellón en el rango de 4 a $15 \mu \mathrm{m}$, permite atribuir el mismo a actividades mecánicas de trasiego (carga, descarga, transporte). Estos procesos son producidos tanto en la dársena del puerto como en las áreas industriales cerámicas, donde también es detectado dicho máximo. Sin embargo, durante los procesos de cocción de cerámica y fusión de fritas, las altas temperaturas alcanzadas en los hornos producen una desestabilización de las estructuras de las materias primas introducidas y neoformación de nuevas fases minerales. Una de las consecuencias es la desestabilización de carbonatos en primer lugar y posteriormente de minerales arcillosos $\mathrm{u}$ otras materias primas, dando lugar a la neoformación, entre otras, de fases tipo plagioclasa, Jordán ${ }^{(12)}$. Las turbulencias generadas en los hornos son causa de la emisión de estas partículas de neoformación de tamaño reducido, y que explicarían el alto porcentaje de plagioclasas detectadas en la fracción fina de las localidades cerámicas. Este hecho es similar al ocurrido en centrales térmicas donde por un proceso similar se produce la neoformación de fases como la mullita a partir de la desestabilización de aluminosilicatos, Havlicek ${ }^{(13)}$, Querol ${ }^{(14)}$.

Las distribuciones obtenidas de la fase mineral caolinita permiten identificar dos orígenes para este compuesto. En el área cerámica dicha fase presenta un máximo principal para tamaños comprendidos entre 1 y $4 \mu \mathrm{m}$. Sin embargo, en el área portuaria del Grao dicho máximo se traslada al intervalo 4 a $15 \mu \mathrm{m}$, tal y como sucede con los minerales feldespato y plagioclasa en la misma localidad, figura 13.

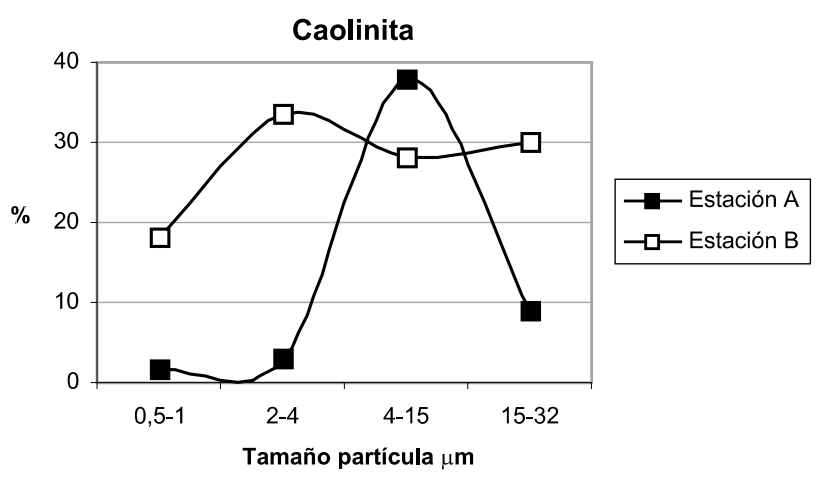

Figura 13. Comparación de las curvas granulométricas de la fase caolinita.

Puede concluirse que el máximo identificado en el Grao debe en parte su origen a las descargas realizadas en el puerto. En relación al valor máximo de caolinita identificado en el área cerámica, su origen se asocia a la manipulación y tratamiento de este material en la industria local. Las pérdidas durante el transporte en cubas y/o los procesos de tratamiento $\mathrm{y}$ atomización son las causas principales asociadas a este máximo. Así, por ejemplo, en la depuración de aire en ciclones durante los procesos de atomización el rendimiento de limpieza en partículas de tamaño inferior a $5 \mu \mathrm{m}$ es muy bajo, Jordán ${ }^{(15)}$.
Respecto a la fase mineral illita, ha sido posible identificar dos valores de máximo porcentaje. Un máximo relativo en el intervalo 1-4 $\mu \mathrm{m}$ de tamaño de partícula , y un máximo absoluto entre 15-32 $\mu \mathrm{m}$. Al igual que en el caso de la caolinita el primer máximo se debe a la manipulación y tratamiento de este material en la industria local. Si se analiza el comportamiento del mineral dolomita en el Grao , presenta los máximos entre 15 y $32 \mu \mathrm{m}$, figura 14 .

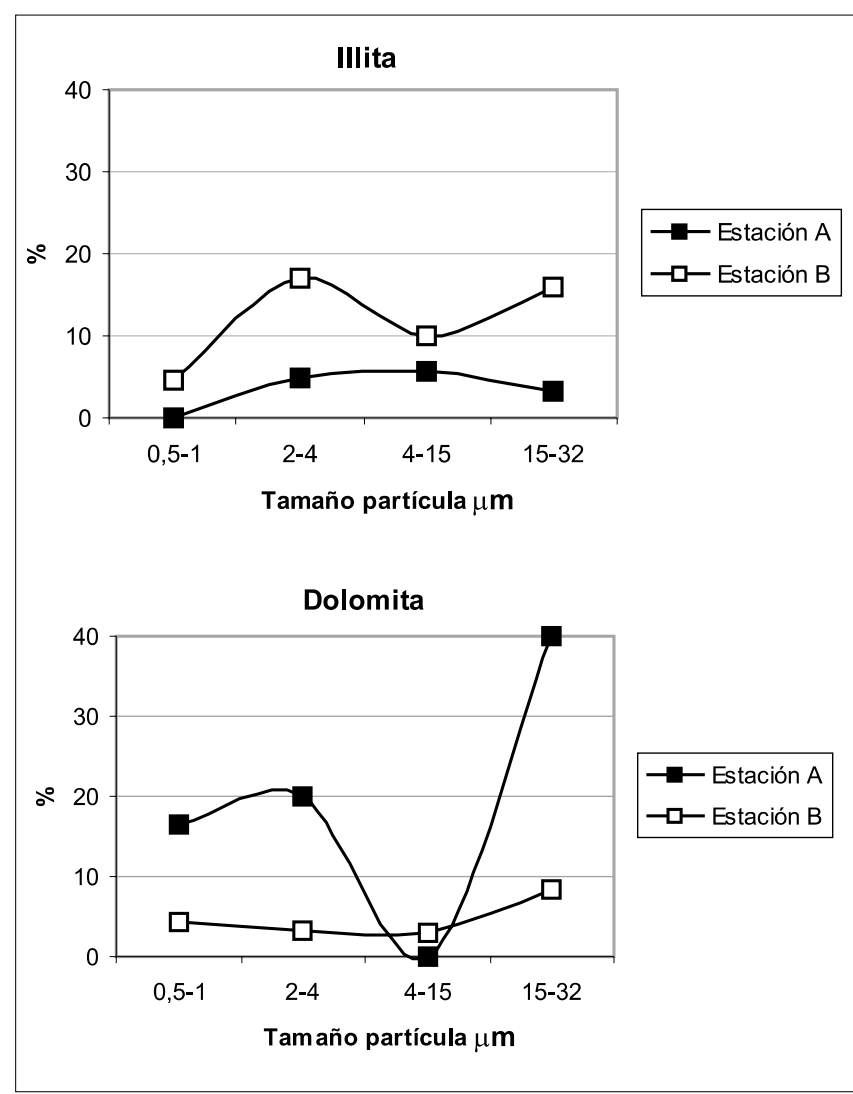

Figura 14. Comparación de las curvas granulométricas de las fases illita y dolomita.

La causa proviene en parte de la erosión natural del sustrato calcáreo-dolomítico de los relieves de Castellón así como del aporte de las explotaciones mineras existentes del mismo material. Las actividades extractivas suelen producir polvo menor a $100 \mu \mathrm{m}$ de tamaño de partícula. Posteriormente, la desecación del suelo y la trituración del material como consecuencia del transporte pueden producir polvo de menor granulometría $(5-20 \mu \mathrm{m})$, Sanfeliu ${ }^{(16)}$. Se deduce que los valores más altos determinados de dolomita y de illita en la fracción de 15 a $32 \mu \mathrm{m}$ son en parte debidos a la interrelación de los aportes por erosión y resuspensión natural, y a las emisiones asociadas a las actividades de extracción de estos materiales ambos característicos de la litología de la zona de estudio.

\section{DISCUSIÓN Y CONCLUSIONES}

Los datos obtenidos en el análisis de la evolución estacional y mensual de los niveles de concentración de partículas mantienen cierta concordancia respecto a estudios aportados por Monn ${ }^{(17)}$ en áreas industriales. En los puntos de muestreo de carácter industrial (estaciones $\mathrm{B}, \mathrm{C}, \mathrm{E}$ ), existe de manera gene- 
ral, y de forma más acusada para las fracciones mayores de 2 $\mu \mathrm{m}$, un aumento de las concentraciones durante la época invernal, y un descenso durante los meses primaverales, para iniciarse nuevamente un aumento de los niveles del verano hacia el otoño. Este mismo comportamiento ya fue detectado por Gómez ${ }^{(18)}$ en la localidad de Onda (estación C). Dicha tendencia va más ligada a la existencia o no de períodos prolongados de estabilidad atmosférica y semiaridez. En el área de estudio tienden a producirse dos intervalos estacionales de bajas precipitaciones, un periodo se sitúa en los meses de verano (julio, agosto, septiembre). Comúnmente, tras episodios de lluvia en octubre, existe en los meses invernales una etapa de estabilidad atmosférica representada por largos periodos con días típicos del régimen de brisas del área, Boix (19), Alvarez ${ }^{(20)}$. Durante estos intervalos estacionales se ven favorecidos los procesos de acumulación de material particulado produciendo el incremento de los niveles de concentración de partículas.

En las dos estaciones de muestreo ubicadas en el sector industrial cerámico, la similitud de los valores y el comportamiento de los niveles de concentración son una indicación de que en primer lugar los niveles de concentración se hallan controlados por los procesos presentes en ese sector industrial. Los factores externos actuarán o bien agravando, es el caso de los efectos de acumulación, o bien mejorando, inestabilidad atmosférica, la situación sobre ese nivel base.

Por el contrario, en las estaciones de muestreo más alejadas de la influencia directa de la actividad industrial (estaciones A,D) se identifica una tendencia al aumento de los niveles de concentración de partículas en los meses de verano, hecho coincidente con los datos expuestos por Boix ${ }^{(19)}$ y Alastuey ${ }^{(21)}$ en el área costero mediterránea.

La interpretación de las curvas de distribución granulométrica ha mostrado dos rangos de tamaño de partícula característicos entre las tres localidades cerámicas estudiadas. En los tres puntos de muestreo existe un enriquecimiento en las partículas comprendidas entre 1 y $8 \mu \mathrm{m}$. Sin embargo en la estación A en Alcora, población ubicada en una ladera de montaña a mayor altitud respecto al núcleo industrial, los picos de máximo se sitúan en el intervalo de 2 a $4 \mu \mathrm{m}$. En las estaciones B y E, situadas al mismo nivel topográfico de base de la actividad industrial, el rango de mayor concentración, recarga y reducción de partículas se sitúa en el rango de 4 a $8 \mu \mathrm{m}$. Así, en estudios realizados sobre particulado atmosférico en áreas caracterizadas por la presencia de centrales térmicas se ha identificado una clara estratificación en altura, Havlicek ${ }^{(13)}$, Davis $^{(22)}$. La concentración de compuestos procedentes de la erosión eólica natural y/o de procesos industriales mecánicos es cuantitativamente más importante a alturas cercanas al nivel del suelo (de 0 a $40 \mathrm{~m}$ ),y disminuye progresivamente al aumentar la altura desde este nivel. A partir de los $60 \mathrm{~m}$ adquieren mayor relevancia aquellos compuestos emitidos por chimenea en procesos industriales de alta temperatura.. Una estratificación similar, puede tener lugar en las áreas adjuntas a centros de producción cerámica, y que por lo tanto explicaría los valores máximos identificados en las distribuciones granulométricas de las estaciones cerámicas estudiadas.

El seguimiento de los niveles en la estación de fondo evidencia dos comportamientos en función del tamaño de partícula. Por un lado las partículas menores de $2 \mu \mathrm{m}$, que con un claro origen antropogénico, muestran un comportamiento estacional muy marcado con máximos en la época estival. En contraposición, las partículas con tamaños entre 4 y $32 \mu \mathrm{m}$ presentan valores muy constantes durante todos los periodos estudiados en condiciones meteorológicas estables. Este hecho ha permitido realizar una estimación del nivel de concentración de fondo del área de estudio. Su origen se asocia a los procesos de aporte natural característicos del área Mediterránea, tal y como se ha reflejado en la composición mineral.

La distribución mineralógica por granulometrías obtenida en el área cerámica indica un enriquecimiento reiterado en una serie de compuestos. Este hecho es un indicativo claro de un origen definido relacionado con dicha actividad cerámica. Los valores máximos de porcentaje de varias fases minerales en las curvas granulométricas han podido asociarse a actividades antropogénicas desarrolladas en la comarca. Las fases con presencia predominante en la fracción menor de $1 \mu \mathrm{m}$ se han atribuido a procesos de neoformación en la atmósfera ( yeso y halita), y a procesos industriales de alta temperatura como en el caso de la plagioclasa $\mathrm{Na}$.

Los valores de caolinita y de illita elevados entre 1 y $4 \mu \mathrm{m}$ pueden relacionarse con pérdidas en procesos de tratamiento de materias primas cerámicas, como el atomizado.

Las actividades de descarga parecen acentuar las concentraciones de minerales como el feldespato $\mathrm{K}$ y la caolinita en el rango de 4 a15 $\mu \mathrm{m}$. Por último, la interrelación de procesos de erosión natural y actividades extractivas intervienen en el aumento de porcentaje de las fases illita y dolomita en la fracción de 15 a $32 \mu \mathrm{m}$.

Con relación a los procesos de aporte natural, se han encontrado cambios en el contenido mineral de muestras captadas en un periodo con condiciones favorables a la intrusión de material del Oeste del Sahara. En las dos estaciones cerámicas muestreadas (Onda y Alcora) en este intervalo de tiempo, se ha identificado un enriquecimiento en calcita para tamaños de partícula de 1 a $4 \mu \mathrm{m}$, y un traslado de los porcentajes máximos de illita y de caolinita al rango de 4 a $8 \mu \mathrm{m}$. Estos cambios en la distribución mineralógica por tamaño de partícula, pueden servir de apoyo en la identificación y evaluación del aporte adicional de material asociado a otros eventos de intrusión con origen en el Atlas, Algeria Central o distintas áreas del Sahara.

\section{AGRADECIMIENTOS}

Los autores agradecen a la Generalitat Valenciana la financiación del proyecto GV97-RN-14-10.

\section{BIBLIOGRAFIA}

1. F. H. Chung. «Quantitative interpretation of X-ray diffraction patterns of mixtures. I. Matrix-flushing method for quantitative multicomponent analysis»). J. of Aplied Cristallography. 7, 519-525 (1974).

2. A. Boix; A. Justo; X. Querol; M.M. Jordan; C. De la Fuente; T. Sanfeliu. «Determinación mineralógica del material particulado inorgánico en suspensión en la atmósfera de Castellón». Geogaceta, 19, 154-157. (1996).

3. X. Querol, A. Alastuey, S. Rodrígez, F. Plana; B. Artíñano, E. Mantilla y A. López-Soler. " Material particulado atmosférico. Fuentes e incertidumbres», pp. 29-39 en III Seminario sobre La calidad del aire en España. Resumen de ponencias. Sevilla Noviembre 1999.

4. A. Avila, M. Alarcon, I. Queralt. « Mineralogical composition of African dust delivered by red rains over northeastern Spain ». Journal of Geophysical Research. 102. [D18]. 21,977-21,996. (1997).

5. X. Querol. « Influencia de eventos naturales en series de PM10. Estado actual de la investigación ». Ponencia en IV Seminario de la calidad del aire en España. Sitges. 7 y 8 de Noviembre 2000.

6. ECWGPM. «Naturals Events », pp. 21-26 en Draft Final Report On Guidance to member states on PM10 Monitoring and Intercomparison with the Reference 
Method. Ed. Martin Willians, Peter Bruckman. Enero 2001.

7. A. Avila, M. Alarcon, I. Queralt. « The chemical composition of dust transported in red rains - Its contribution to the biogeochemical cycle of a holm oak forest in Catalonia (Spain) »Atmospheric Environment 32, [2], 179-191. 1998

8. .W.T. Sturges; R. Harrison and L.A. Barrie. « Semi-cuantitative X-ray diffraction analysis of size fractionated atmospheric particles» Atmospheric Environment, 23, [5], 1083-1098. 1988

9. G. Bergametti; A.L. Dutot; P. Buat-Menard and R. Losno. « Seasonal variability of the elemental composition of atmospheric aerosol particles over the Northwestern Mediterranean» Tell Us, 41B, 353-361. 1989

10. N. V. Gillani; S. Kohli, and W. E. Wilson «Gas-to-particle conversion of sulphur in power plant plumes I. Parametrization of the conversion rate for dry, moderately polluted ambiente conditions»' Atmospheric Environment 15, 2293-2313. 1981

11. G. Zhou and K. Taraki. «Seasonal variation of gypsum in aerosol and its effect on the acidity of wet precipitation on the Japan sea side of Japan» Atmospheric Environment, 30, [19], 3301-3308. 1996

12. M.M. Jordán; C. De la Fuente; A. Boix y J. Ma Rincón. «Estudio de la dinámica mineral en probetas cerámicas» pp. 243-255 en Caracterización química y mineralógica de materias primas de Castellón de interés en la composición de pastas cerámicas. Ed. Fundación Dávalos-Fletcher. Impr. Litografía de Castellón, S.A. 1997

13. L. D. Havlicek; R.Pribil; O. Dubovsky; L. Dobiasova; P. Sedlak. « Chemical and mineralogical composition of solid fraction of ambient aerosol at different levels (Kopisty near Most, NW Bohemia) ». Atmospheric Environment, 34, [19], 3237-3244. 2000

14. X. Querol, A. Alastuey, A, Lopez-Soler, E. Mantilla and F. Plana. «Mineral composition of atmospheric particulates around a large coal-fired power station» Atmospheric Environment, 30, [21], 3557-3572. 1996

15. M.M. Jordan; C. Alvarez, E.T. Gómez; T. Sanfeliu. «Caracterización del material particulado atmosférico sedimentable: delimitación de subambientes») Retema Año XII № 68. Enero-febrero 1999.

16. T. Sanfeliu; M.M. Jordán; A. Boix. « Aportación al estudio del impacto ambiental originado por la explotación de arcillas cerámicas del Cretácico de la provincia de Castellón» pp. 31-77 en Ciencia y Tecnología de recursos naturales y medio ambiente, Vol I. Ed. Publicaciones del Excmo. Ayuntamiento de Castellón de la Plana. 1996

17. $\mathrm{CH}$. Monn; O. Braendly; G. Schaeppi; Ch. Schindler; U. Ackerman; Ph Leuenberger and Sapaldia Team. « Particulate matter $<10 \mu \mathrm{m}$ (PM10) and total suspended particulates (TSP) in urban, rural and Alpine air in Switzerland» Atmospheric Environment, 29, 2565-2573. 1995.

18. E.T. Gómez« Caracterización mineralógica y química de las partículas atmosféricas en un área industrial» Tesis de licenciatura. Universidad Jaume I. Castellón. Trabajo inédito. (1999).

19. A. Boix «Caracterización físico-química del particulado en suspensión » pp. 115-130 en Contaminación atmosférica en la Plana de Castellón. Exc. Ajuntament de Castelló de la Plana. Ed. Graphic Group, S.A. 1996.

20. C. Alvarez. «Caracterización del material particulado sedimentable de Castellón»». Tesis de licenciatura. Universidad Jaume I. Castellón. Trabajo inédito. 1997.

21. A. Alastuey, E. Mantilla, X. Querol, S. Rodriguez. « Estudio y evaluación de la contaminación atmosférica por material particulado en España: necesidades derivadas de la propuesta de la diretiva del consejo relativa a partículas PM10 y Pm2.5 e implicaciones en la industria cerámica ». Bol. Soc. Esp. de Cerámica y Vidrio. 39 [1] 135-141 (2000)

22. B.L. Davis. " $X$-ray diffraction analysis and source apportionment of Denver aerosol». Atmospheric Environment 18, 2197-2208. 1984.

\section{Notas}

MPS: Material particulado en suspensión

${ }^{2}$ PST: Partículas totales en suspensión

${ }^{3} \mathrm{PM}_{10}$ : Fracción del PST inferior a $10 \mu \mathrm{m}$

${ }^{4} \mathrm{PM}_{25}$ : Fracción del PST inferior a $2.5 \mu \mathrm{m}$

${ }^{5} \mathrm{PM}_{1}$ : Fracción del PST inferior a $1 \mu \mathrm{m}$

${ }^{6}$ ECWGPM: European Comission Working Group on particulate matter

Recibido: 16.11 .00

Aceptado: 02.03.01
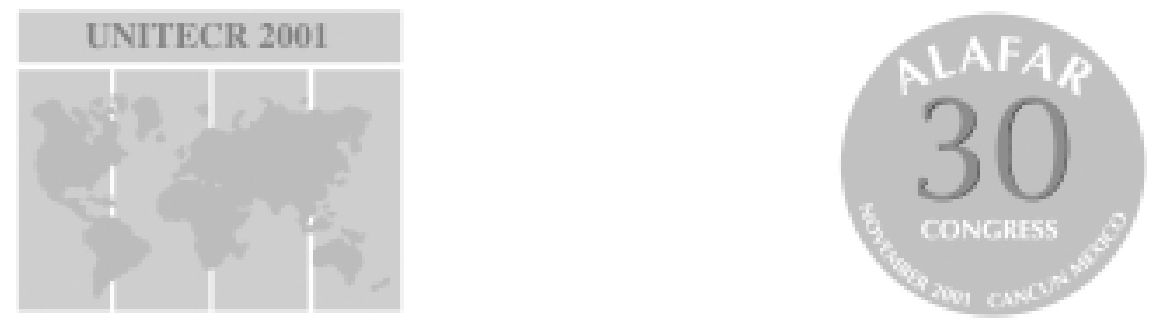

\title{
UNITECR 2001 CONGRESS.
}

7TH Biennial Worldwide Conference on Refractories

\author{
Cancún, Quintana Roo, México \\ November 4-8, 2001.
}

TECHNICAL COMITTEE

e-mail: techcommtt@hwr.com.mx

FAX: +52 (8) 4117299 